\title{
Effects of Replacing Inorganic Trace Minerals with Organic Ones (HimChelate-P) in Layer Diets on Production Performance, Egg Quality Traits, and Biochemical Parameters
}

\author{
Bhagwat Vishwanath G*, Santosh Kumar V and Rangesh Paramesh \\ Himalaya Wellness Company, Makali, Karnataka, India \\ *Corresponding Author: Bhagwat Vishwanath G, Himalaya Wellness Company, \\ Makali, Karnataka, India.
}

Received: July 02, 2021

Published: July 26, 2021

(C) All rights are reserved by Bhagwat

Vishwanath G., et al.

\begin{abstract}
This study was designed to evaluate the effects of HimChelate-P on production performance, biochemical parameters, and egg quality parameters in BV-300 layer birds. In this study, one hundred twenty 50-week-old BV 300-layer birds were enrolled and randomly assigned to three groups, namely, T1, T2, and T3, with two replicates having 20 birds each. T1, T2, and T3 were raised on normal commercial feed and concurrently supplemented with inorganic trace minerals (ITMs) at $1000 \mathrm{~g} / \mathrm{ton}$ of feed to T1 and competitor organic trace minerals (OTMs) and HimChelate-P (HC-P) at $500 \mathrm{~g} /$ ton of feed to T2 and T3, respectively. Hen-day egg production significantly improved following supplementation with HimChelate-P as compared with ITMs. The egg weight increased by $3.50 \%$ following supplementation with HimChelate-P compared with ITMs. A significant increase in eggshell thickness (mm) was observed in T2 $(p<0.05)$ and T3 $(p<0.001)$ on week 4 and T3 $(p<0.001)$ on week 5. In this study, T3 had numerical increases in serum protein, albumin, and globulin levels and the albumin-globulin ratio compared with T1. Serum copper and manganese concentrations decreased in T2 and T3 compared with T1. Moreover, the serum level of zinc decreased in T2 only. In conclusion, supplementation with HimChelate-P improves the overall health status, production performance, and egg quality parameters of BV300 layer birds compared with ITMs and OTMs. Hence, replacing ITM and OTM products with HimChelate-P at a dose of 500 g/ton could be recommended for augmenting production performance, improving the overall health status, and enhancing egg quality in BV 300-layer birds.
\end{abstract}

Keywords: HimChelate-P; Inorganic Trace Minerals; Organic Trace Minerals; Hen-day Egg Production; Egg Quality; BV-300 Layers

\section{Introduction}

Trace minerals are important in producing proteins, which are involved in several biochemical processes, antioxidative properties, hormone secretion pathways, eggshell formation, and immune defense system [1,2]. Commercial diets are typically supplemented with inorganic trace minerals (ITMs) at a proportion greater than the recommendation by the National Research Council (NRC) [3]. Meanwhile, using of ITMs holds several risks, including the formation of insoluble complexes with phytic phosphorus, low digest- ibility, and environmental pollution via their excretion in urine and feces [4].

Organic trace minerals (OTMs) are minerals linked with amino acids and become stable and more bioavailable [5]. Studies have shown that the absorption rate of OTMs in the gut was greater than that of ITMs [6]. Moreover, trace minerals are substantial in laying hens due to their role in various biochemical processes demanded for normal growth, maturation, and eggshell deposition. Mineral nutrition is a remarkable side for the optimum egg production in 
Effects of Replacing Inorganic Trace Minerals with Organic Ones (HimChelate-P) in Layer Diets on Production Performance, Egg Quality Traits, and Biochemical Parameters

commercial layers. Maintaining the optimum mineral concentration in diets is essential for getting high-quality eggs for sale [7].

Paik (2001) has evaluated the use of organic zinc, copper, and manganese, either individually or in combination, and observed improvement in the production performance of birds fed with organic copper and the combination of these three metals in an organic complex [8]. Additionally, Xavier., et al. (2004) have observed improvements in performance and egg quality of brown layers during the second laying cycle. These authors have verified the beneficial effects of using organic selenium, zinc, and manganese combinations on these parameters [9].

Furthermore, eggshell quality is related to macrominerals (i.e., calcium and phosphorus) and vitamin D3, but nowadays, trace elements are also essential in the mineralization process; zinc, copper, and manganese organic or inorganic sources could affect the mechanical properties of eggshells [10]. High breaking strength of eggshell and the absence of shell defects are essential for protection against the penetration of pathogenic bacteria, such as Salmonella spp. into eggs. Copper, zinc, and manganese are biologically important in poultry formation of enzymes, immune response, bone development, integrity, eggshell formation, and protection against oxidative stress, which are all mineral-dependent processes [11].

Current studies have indicated that feeding laying hens with organic sources of trace minerals can improve egg quality, as well as egg production and growth [12]. Moreover, several studies have shown that OTMs have greater bioavailability than ITMs. Some minerals are necessary in small quantities to improve eggshell quality. Zinc, manganese, and copper are necessary for the organic matrix of eggshells and subsequently the mechanical properties. Additionally, they are involved in the interaction with calcium crystals during shell formation $[13,14]$. Furthermore, in a recent review of literature conducted by Bhagwat., et al. the tremendous medicinal potentials of phytogenic feed additives (PFAs), namely, antimicrobial, antioxidant, adaptogenic, and immunomodulatory, could be extracted with the recent advances in science and technology, and hence, there is a resurgence to develop PFAs as a cocktail of organic minerals to improve the overall health status of poultry birds and augment their productivity, which, in turn, helps the poultry industry to grow decisively and economically [15]. Therefore, in this study, HimChelate-P, a chelated mineral supplement fortified with herbs (developed by Himalaya Wellness Company, Bengaluru,
India), was chosen for screening in vivo where its efficacy in enhancing production performance, biochemical parameters, and egg quality was assessed in BV-300 layer birds.

\section{Material and Methods}

Test product

HimChelate-P is composed of minerals, namely, zinc, manganese, iron, copper, iodine, chromium, and selenium and fortified with herbs, namely, Cissus quadrangularis, Asparagus racemosus, Allium sativum, Emblica officinalis, and Withania somnifera.

\section{Ethical approval}

The study protocol and ethical use of experimental animals were approved by the Institutional Animal Ethics Committee of Himalaya Wellness Company (Protocol No. AHP/P/11/19).

\section{Experimental birds and diets}

One hundred twenty 50-week-old BV-300 layer birds were purchased from M/s Shareen Layer Farm, Near Nelamangala, Bangalore. Each group was then replicated to two subgroups, with each having 20 birds. The experimental diet was formulated based on the prevailing nutritional standards for egg-laying chicken (BV300, Venkateswara Hatchery Pvt. Ltd., Hyderabad, India). ITMs and OTMs and HimChelate-P were mixed with the basal diet at the rate of $1000 \mathrm{~g} /$ ton and $500 \mathrm{~g} /$ ton, respectively. The nutrient composition of the basal diet is shown in table 1 .

\section{General layer birds' husbandry practices}

The standard management practices required for BV-300 layers were followed during the experiment. The experimental birds were reared in four-bird colony cages $\left(18^{\prime \prime} \times 12^{\prime \prime} \times 15^{\prime \prime}\right)$ using the stair step cage system. Each cage had access to two nipple drinkers and feeders fixed. The potable drinking water and experimental diets were provided to the birds' ad libitum throughout the study period. The recommended standard BV-300-layer bird's vaccination schedule was followed.

\section{Study design}

The BV-300 layer birds enrolled in this study were randomly assigned to three groups, namely, T1, T2, and T3, with two replicates having 20 birds each. T1, T2, and T3 were raised on normal commercial feed and concurrently supplemented with ITM at $1000 \mathrm{~g} /$ ton of feed to T1 and OTM and HimChelate-P at $500 \mathrm{~g} /$ ton of feed to T2 and T3 (Table 2). 
Effects of Replacing Inorganic Trace Minerals with Organic Ones (HimChelate-P) in Layer Diets on Production Performance, Egg Quality Traits, and Biochemical Parameters

\begin{tabular}{|l|c|}
\hline Metabolizable energy (kcal/kg) & 2750.00 \\
\hline Crude protein (\%) & 16.80 \\
\hline Lysine (\%) & 0.80 \\
\hline Methionine (\%) & 0.40 \\
\hline Met + cyst (\%) & 0.67 \\
\hline Threonine (\%) & 0.56 \\
\hline Tryptophan (\%) & 0.18 \\
\hline Digestible amino acids & \\
\hline Dig. Lysine (\%) & 0.71 \\
\hline Dig. Methionine (\%) & 0.38 \\
\hline Dig. Met + Cyst (\%) & 0.60 \\
\hline Dig. Threonine (\%) & 0.48 \\
\hline Dig. Tryptophan (\%) & 0.155 \\
\hline Major minerals & \\
\hline Calcium (\%) & $3.00-4.00$ \\
\hline Available Phosphorus (\%) & 0.42 \\
\hline Sodium minimum (\%) & 0.15 \\
\hline Chlorine minimum (\%) & 0.14 \\
\hline
\end{tabular}

Table 1: Nutritional value of BV-300 layer basal diet. kcal: Kilocalorie; Kg: Kilogram; \%: Percentage.
Production parameters

The number of eggs laid down by the birds was recorded on weeks $1,2,3,4,5$, and 6 of feed supplement administration and expressed in hen-day egg production (HDEP). HDEP was calculated using the following formula:

HDEP = (total number of eggs produced on a day/total number of hens present on that day) $\times 100$

\section{Egg quality parameters}

- $\quad$ Egg shell thickness: Egg shell thickness was measured using a digital vernier caliper on weeks 1, 2, 3, 4, 5, and 6 of feed supplement administration.

- $\quad$ Egg weight: The egg weight of each group was measured using a digital weighing scale, and the average egg weight of each group was calculated.

\section{Blood collection and serum separation}

Blood samples (approximately $2 \mathrm{~mL}$ ) were collected in a plain centrifuge tube (vacutainer tube), and serum was separated by centrifugation at $2000 \mathrm{rpm}$ for $5 \mathrm{~min}$ and stored at $-20^{\circ} \mathrm{C}$ until assay of biochemical parameters and analysis of Newcastle disease (ND) and Infectious Bursal Disease (IBD) antibody titer. The blood

\begin{tabular}{|c|c|c|c|c|c|}
\hline Group & Treatment & $\begin{array}{c}\text { Duration of } \\
\text { treatment }\end{array}$ & $\begin{array}{l}\text { Number of } \\
\text { replicates }\end{array}$ & $\begin{array}{c}\text { Number of } \\
\text { chicks/replicate }\end{array}$ & $\begin{array}{c}\text { Number of } \\
\text { chicks/groups }\end{array}$ \\
\hline T1 (ITMs) & $\begin{array}{c}\text { Basal diet + ITMs (1000 g/ } \\
\text { ton) }\end{array}$ & 42 days & 2 & 20 & 40 \\
\hline T2 (COTMs) & Basal diet + OTMs (500 g/ton) & 42 days & 2 & 20 & 40 \\
\hline T3 (HC-P) & Basal diet + HC-P (500 g/ton) & 42 days & 2 & 20 & 40 \\
\hline
\end{tabular}

Table 2: Study design.

sample was collected from the brachial vein of chicks (10 chicks/ group) on day 35 :

- Assay of serum biochemical parameters: The assay of biochemical parameters $(n=10)$, namely, total protein, globulin, albumin, and albumin-globulin $(\mathrm{A} / \mathrm{G})$ ratio measured using standardized kit-based assay methods using an automated biochemical analyzer (EM360 Erba Mannheim, Transasia Biomedicals Ltd., Mumbai, India).
- Serum mineral estimation: Manganese, copper, and zinc levels were estimated in serum samples using an inductively coupled plasma optical emission spectrometer following the manufacturer's guidelines [16].

\section{Statistical analysis}

The data are expressed as mean \pm standard error of the mean. Data were subjected to statistical analysis using one-way analysis of variance, followed by Dunnett's multiple comparison tests, to 
Effects of Replacing Inorganic Trace Minerals with Organic Ones (HimChelate-P) in Layer Diets on Production Performance, Egg Quality Traits, and Biochemical Parameters

draw a comparison between the control and treatment groups. $P$ values of less than or equal to 0.05 were used to denote statistical significance. Statistical Package for the Social Sciences (version 20; IBM Corp., Armonk, NY, USA) was used for all statistical analyses.

\section{Results and Discussion}

Production parameters

HDEP numerically and significantly increased after supplementation with OTMs (T2) $(p<0.01)$ and HimChelate-P (T3) ( $\mathrm{p}<$ 0.001 ) on weeks 1 and 4, respectively, compared with that in T1. Whereas, on week 6, HDEP increased only in T3 compared with that in $\mathrm{T} 1$ (Table 3). The egg production performance-enhancing effects of HimChelate-P could be attributed to its higher bioavailability from its OTM composition in synergy with herbal actives than from inorganic source, namely, ITMs. Additionally, a study has reported production performance augmentation following supple- mentation with chelated trace minerals. Yenice., et al. (2015) have reported that the production performance and eggshell quality in laying hens improved following copper methionine supplementation compared with those in birds supplemented with copper sulfate [17]. Harbaugh and Sanford (1970) have reported that HDEP increased following supplementation of layer diet with zinc methionine [18]. Xavier., et al. (2004) have also reported that that using organic selenium, zinc, and magnesium combinations improved the production performance and egg quality in brown layers during the second laying cycle. 9 Conversely, da Silva Sechinato., et al. (2006) have reported that organic minerals had no effects on the production performance and egg quality compared with inorganic minerals in 48- to 60-week-old layers [19]. Payane., et al. (2005) have revealed that the response to mineral supplementation depends on their concentrations in the basal diet [20].

\begin{tabular}{|c|c|c|c|c|c|c|}
\hline Group & Week 1 & Week 2 & Week 3 & Week 4 & Week 5 & Week 6 \\
\hline $\begin{array}{l}\text { T1-ITM } \\
(1000 \mathrm{~g} / \text { ton })\end{array}$ & $81.43 \pm 2.16$ & $86.19 \pm 1.98$ & $82.86 \pm 1.84$ & $78.57 \pm 1.43$ & $82.86 \pm 1.53$ & $80.00 \pm 1.78$ \\
\hline $\begin{array}{l}\text { T2-0TM } \\
\text { (500 g/ton) }\end{array}$ & $85.24 \pm 0.99$ & $83.33 \pm 1.45$ & $84.76 \pm 1.23$ & **83.81 \pm 1.13 & $82.86 \pm 0.87$ & $80.48 \pm 1.53$ \\
\hline $\begin{array}{l}\text { T3-HC-P } \\
\text { (500 g/ton) }\end{array}$ & $86.67 \pm 1.45$ & $89.05 \pm 0.95$ & $86.19 \pm 1.13$ & $* * * 85.71 \pm 0.95$ & $84.76 \pm 1.23$ & $83.81 \pm 1.13$ \\
\hline
\end{tabular}

Table 3: Effects of HimChelate-P on hen-day egg production in BV-300 layer birds.

Values are expressed as mean \pm standard error of the mean; $n=7$.

${ }^{* *} \mathrm{p}<0.01$, and ${ }^{* * *} \mathrm{p}<0.001$ (significantly increased) compared with T1 based on one-way analysis of variance, followed by Dunnett's multiple comparison test.

\section{Egg quality parameters}

The egg weight increased by $3.50 \%$ following supplementation with HimChelate-P compared with that following supplementation with ITM (Figure 1). A significant increase in eggshell thickness $(\mathrm{mm})$ was observed in T2 $(\mathrm{p}<0.05)$ and T3 $(\mathrm{p}<0.001)$ on week 4 and T3 $(\mathrm{p}<0.001)$ on week 5 compared with that in T1. However, a numerical increase in eggshell thickness ( $\mathrm{mm}$ ) was observed only in T3 on weeks 2 and 3 (Table 4). These findings could be attributed to the chelated trace minerals in HimChelate$P$ fortified with herbs; since trace minerals affect eggshell quality due to their catalytic properties as constituents of key enzymes involved in the processes of membrane and eggshell synthesis or by direct interaction with calcium crystals during eggshell formation. These findings were comparable with those in various studies reported in the literature. Hudson (2004) has reported that feeding layers with zinc-amino acid complexes increased egg-specific gravity and reduced the number of cracked eggs compared with in those supplemented with inorganic zinc sources [21]. Ceylan and Scheideler (1999) have also reported that the percentage of cracked eggs during processing reduced following supplementa- 
Effects of Replacing Inorganic Trace Minerals with Organic Ones (HimChelate-P) in Layer Diets on Production Performance, Egg Quality Traits, and Biochemical Parameters

\begin{tabular}{|l|c|c|c|c|c|c|}
\hline \multicolumn{1}{|c|}{ Group } & Week 1 & Week 2 & Week 3 & Week 4 & Week 5 & Week 6 \\
\hline T1-ITM & $0.45 \pm 0.01$ & $0.48 \pm 0.01$ & $0.48 \pm 0.02$ & $0.44 \pm 0.01$ & $0.43 \pm 0.01$ & $0.48 \pm 0.00$ \\
$(1000 \mathrm{~g} /$ ton $)$ & $0.41 \pm 0.01$ & $0.49 \pm 0.01$ & $0.45 \pm 0.01$ & $* 0.49 \pm 0.01$ & $0.46 \pm 0.01$ & $0.50 \pm 0.02$ \\
\hline $\begin{array}{l}\text { T2-0TM } \\
(500 \mathrm{~g} / \text { ton })\end{array}$ & $0.44 \pm 0.02$ & $0.48 \pm 0.01$ & $0.52 \pm 0.02$ & $* * * 0.52 \pm 0.02$ & $* * * 0.54 \pm 0.02$ & $0.53 \pm 0.01$ \\
\hline $\begin{array}{l}\text { T3-HC-P } \\
(500 \mathrm{~g} / \text { ton })\end{array}$ & & & & \\
\hline
\end{tabular}

Table 4: Effects of HimChelate-P on eggshell thickness in BV-300 layer birds.

Values are expressed as mean \pm standard error of the mean; $n=6$.

${ }^{*} \mathrm{p}<0.05$, and ${ }^{* * *} \mathrm{p}<0.001$ (significantly increased) compared with T1 based on one-way analysis of variance, followed by Dunnett's multiple comparison test.

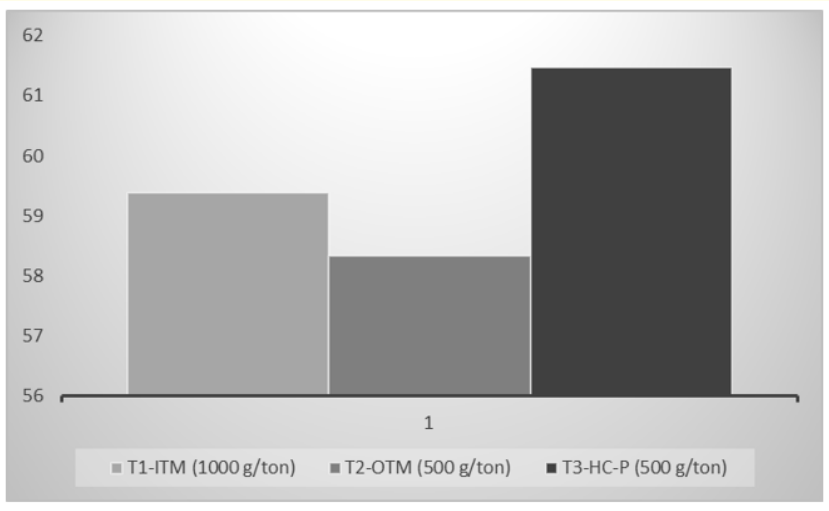

Figure 1: Effects of HimChelate-P on egg weight in BV-300 layer birds.

tion of layer diets with zinc and manganese [22]. Dale and Strong (1998) have reported that when supplementation with OTMs was replaced by inorganic sources, egg-specific gravity significantly decreases [23]. However, in contrast to our findings, Mabe., et al. (2003) did not find any changes in eggshell yield with the use of organic zinc or manganese [24]. Furthermore, according to Upadhaya SD., et al. (2016), the rate of cracked eggs was not affected by dietary supplementation with ionized or chelated water-soluble mineral mixture [25].

\section{Serum biochemical parameters}

Blood biochemical parameters are critical indicators of animal nutritional status. In this study, following supplementation with HimChelate-P, a numerical increase in serum protein $(\mathrm{g} / \mathrm{dL})$, albumin $(\mathrm{g} / \mathrm{dL})$, and globulin $(\mathrm{g} / \mathrm{dL})$ levels and the $\mathrm{A} / \mathrm{G}$ ratio was observed compared with those following supplementation with ITMs (Table 5). These findings implied that supplementation with HimChelate-P and OTMs at $500 \mathrm{~g} /$ ton of feed was comparable with each other in terms of biochemical parameter-enhancing effects. Feng., et al. (2010) have found identical concentrations of total protein when feeding a diet with lower levels of organic zinc compared with its sulfates, even though the latter was four times higher than its organic source [26]. One possibility is that minerals play a major role in the body enzyme system, physiology, metabolism, and growth and are necessary to promote protein synthesis; for example, zinc can improve the digestibility of feed by activating pancreatic digestive enzymes, subsequently resulting in higher levels of glucose in the blood [27,28]. Accordingly, albumin concentration increased as mineral supplementation levels increased since albumin is the main transporter of minerals in the serum $[29,30]$.

\section{Serum mineral content}

Serum copper (ppm) and manganese concentrations decreased in T2 and T3 compared with those in T1. Serum zinc (ppm) levels decreased only in $\mathrm{T} 2$ compared with those in $\mathrm{T} 1$ (Table 6). These findings delineated that trace minerals supplemented through 
Effects of Replacing Inorganic Trace Minerals with Organic Ones (HimChelate-P) in Layer Diets on Production Performance, Egg Quality Traits, and Biochemical Parameters

37

\begin{tabular}{|l|c|c|c|c|}
\hline \multicolumn{1}{|c|}{ Groups } & Total protein $\mathbf{( g / d L ) ~ ( g / d L ) ~}$ & Albumin (g/dL) & Globulin (g/dL) & A/G ratio (g/dL) \\
\hline T1-ITM (1000 g/ton) & $4.88 \pm 0.11$ & $1.40 \pm 0.02$ & $3.46 \pm 0.13$ & $0.37 \pm 0.05$ \\
\hline T2-OTM (500 g/ton) & $4.65 \pm 0.53$ & $1.33 \pm 0.15$ & $3.32 \pm 0.38$ & $0.40 \pm 0.01$ \\
\hline T3-HC-P (500 g/ton) & $5.89 \pm 0.31$ & $1.63 \pm 0.06$ & $4.26 \pm 0.38$ & $0.39 \pm 0.03$ \\
\hline
\end{tabular}

Table 5: Effects of HimChelate-P on serum biochemical parameters in Cobb-400 Y broiler chickens.

Values are expressed as mean \pm standard error of the mean; $\mathrm{n}=10$.

$\mathrm{P}>0.05$ compared with T1 based on one-way analysis of variance, followed by Dunnett's multiple comparison test.

organic sources (e.g., HimChelate-P) were less excreted than inorganic sources, and hence, trace minerals from organic sources could be bioavailable and retained inside the body for various metabolic functions. The results of this study corroborate the findings of Yenice E., et al. (2015), who have reported a reduction in mineral excretion when inorganic trace mineral sources were replaced by organic mineral sources in layer diets. Furthermore, they have demonstrated higher bioavailability of copper, manganese, zinc, chromium, and calcium, determined by their serum levels in layers fed with diets containing OTMs [31]. Leeson and Caston (2008) have observed $66 \%$ and $78 \%$ reductions in the excretion of zinc and manganese, respectively, without affecting the production performance of layer birds following supplementation of layer diet with OTM, namely, proteinates, at $20 \%$ of the ITM level, and therefore recommended supplementation with minimal levels of OTMs as an alternative to reduce trace mineral excretion [32]. The higher bioavailability of organic trace mineral sources compared with inorganic sources promotes high enzyme activity and higher trace mineral retention [33] and lower excretion even when added to diets at levels below those used for ITM inclusion [34]. This may be explained by the fact that in addition to the normal ion absorption mechanisms in the intestines, chelated minerals are absorbed through the same pathways as the organic molecules with which they are complexed, thereby avoiding competition among minerals for the same carrier and making them more readily transportable and absorbable for subsequent utilization by the body [35]. According to Manangi MK., et al. (2012), the use of OTMs offers the opportunity to reduce the environmental impact caused by the poultry industry, among other benefits [36].

Since ancient times, plants and plant parts have a pivotal role as medicine sources for indigenous poultry production systems. The existing indigenous technical knowledge inherited from past gen-

\begin{tabular}{|l|c|c|c|}
\hline \multicolumn{1}{|c|}{ Groups } & $\begin{array}{c}\text { Manganese } \\
\text { (ppm) }\end{array}$ & $\begin{array}{c}\text { Copper } \\
\text { (ppm) }\end{array}$ & $\begin{array}{c}\text { Zinc } \\
\text { (ppm) }\end{array}$ \\
\hline T1-ITM (1000 g/ton) & 0.09 & 0.32 & 3.03 \\
\hline T2-OTM (500 g/ton) & 0.07 & 0.25 & 2.81 \\
\hline T3-HC-P (500 g/ton) & 0.08 & 0.28 & 3.46 \\
\hline
\end{tabular}

Table 6: Effects of HimChelate-P on serum mineral concentrations in Cobb-400 Y broiler chickens.

Values are expressed as mean; $\mathrm{n}=16$.

erations has sustained the local poultry production system $[37,38]$. Various researchers have explored indigenous medicinal herbs and plant extracts (e.g. garlic, cinnamon, tulasi, ginger, yucca, turmeric, neem, thyme, rosemary, and lemon) to enhance poultry health and augment the production performance with favorable results [3943]. Moreover, a literature survey has shown that dietary supplementation with herbal preparations positively affects performance parameters, such as body weight gain, feed intake, feed efficiency, and carcass traits; biochemical parameters; and immune responses among poultry birds [44]. The synergistic and antagonistic effects of PFAs on poultry have been supported by various studies reported in the literature [45-51].

Moreover, Bhagwat., et al. in a review of literature, have delineated the role of chelated minerals and PFA cocktail supplementation in improving the overall health status and production performance of poultry birds and its economic effects in the poultry industry and recommended to develop PFAs as a cocktail of organic minerals to improve the overall health status of poultry birds and augment their productivity, which, in turn, helps the poultry industry to grow decisively and economically [15]. Following the recommendations by Bhagwat., et al. HimChelate-P was developed by Himalaya Wellness Company (Bengaluru, India). HimChelate-P

Citation: Bhagwat Vishwanath G., et al. "Effects of Replacing Inorganic Trace Minerals with Organic Ones (HimChelate-P) in Layer Diets on Production Performance, Egg Quality Traits, and Biochemical Parameters". Acta Scientific Veterinary Sciences 3.8 (2021): 32-40. 
Effects of Replacing Inorganic Trace Minerals with Organic Ones (HimChelate-P) in Layer Diets on Production Performance, Egg Quality Traits, and Biochemical Parameters

is composed of minerals, namely, zinc, manganese, iron, copper, iodine, chromium, and selenium, and fortified with herbs, namely, Cissus quadrangularis, Asparagus racemosus, Allium sativum, Emblica officinalis, and Withania somnifera. Overall, our findings revealed that supplementation with HimChelate-P augmented the production performance, improved the overall health status, and enhanced the egg quality in BV-300 layer birds. Furthermore, the bioavailability of HimChelate-P was superior to that of its inorganic counterpart. These findings conform to the recommendations by Bhagwat., et al. [15].

\section{Conclusion}

In conclusion, supplementation with HimChelate-P improved the overall health status, production performance, and egg quality parameters in BV-300 layer birds as compared with ITMs and other OTMs. Hence, replacing ITM and OTM products with HimChelate$\mathrm{P}$ at a dose of $500 \mathrm{~g} /$ ton could be recommended for augmenting production performance, improving the overall health status, and enhancing egg quality in BV-300 layer birds.

\section{Acknowledgments}

The authors acknowledge the encouragement provided by Dr. Rajesh Kumawat, Head, Medical Services and Clinical Development, Dr. U. V. Babu, Head R\&D, Himalaya Wellness Company, Bengaluru, Karnataka.

\section{Competing Interests}

The authors declare that they have no competing interests.

\section{Bibliography}

1. Tom Dieck H., et al. "Changes in rat hepatic gene expression in response to zinc deficiency as assessed by DNA arrays". The Journal of Nutrition 133.4 (2003): 1004-1010.

2. Yatoo MI., et al. "Role of trace elements in animals: a review". Veterinary World 3.12 (2013): 963-967.

3. NRC. "Nutrient requirement of poultry". 9th reviewed Washington, DC, USA: National Academy Press (1994).

4. Yan F and Waldroup PW. "Evaluation of Mintrex ${ }^{\circledR}$ manganese as a source of manganese for young broilers". International Journal of Poultry Science 5.8 (2006): 708-713.

5. AAFCO Association of American Feed Control Officials. Official publication, Atlanta, GA (2005): 307-308.
6. Ji F., et al. "Effect of manganese source on manganese absorption by the intestine of broilers". Poultry Science 85.11 (2006): 1947-1952.

7. Mabe I., et al. "Supplementation of a corn-soybean meal diet with manganese, copper, and zinc from organic or inorganic sources improves eggshell quality in aged laying hens". Poultry Science 82.12 (2003): 1903-1913.

8. Paik I. "Application of chelated minerals in animal production". Asian-Australasian Journal of Animal Sciences 14 (2001): 191198.

9. Xavier GB., et al. "Performance of layers fed diets containing organic selenium, zinc and manganese, during a second cycle of production". Proceedings of the Annual Symposium on Biotechnology in the feed industry, 20th (2004): 19.

10. Swiatkiewicz S and Koreleski J. "The effect of zinc and manganese source in the diet for laying hens on eggshell and bones quality". Veterinarni Medicina 53.10 (2008): 555-563.

11. Dobrzański Z., et al. "Bioavailability of selenium and zinc supplied to the feed for laying hens in organic and inorganic form. EJPAU, ser". Animal Husbandry 6.2 (2003): 1-3.

12. Uni Z., et al. "Nutritional limitations during poultry embryonic development". Journal of Applied Poultry Research 21.1 (2012): 175-184.

13. Yildiz A0., et al. "Effects of dietary organic and inorganic manganese supplementation on performance, egg quality and bone mineralisation in laying hens". Revue de Medecine Veterinaire 162.10 (2011): 482-488.

14. Stefanello C., et al. "Productive performance, eggshell quality, and eggshell ultrastructure of laying hens fed diets supplemented with organic trace minerals". Poultry Science 93.1 (2014): 104-113.

15. Bhagwat VG., et al. "Cocktail of chelated minerals and phytogenic feed additives in the poultry industry: A review". Veterinary World 14.2 (2021): 364-371.

16. Boss $\mathrm{CB}$ and Fredeen KJ. "Concepts, instrumentation, and techniques in inductively coupled plasma optical emission spectrometry". $3^{\text {rd }}$ ed. PerkinElmer Inc., Shelton, CT (2004). 
17. Yenice E., et al. "Effects of dietary organic or inorganic manganese, zinc, copper and chrome supplementation on the performance, egg quality and hatching characteristics of laying breeder hens". Ankara Üniversitesi Veteriner Fakültesi Dergisi 62.1 (2015): 63-68.

18. Harbaugh DD. "The effect of various levels of zinc-methionine supplement on flock performance, egg size and shell quality". Poultry Science 49 (1970): 1393.

19. da Silva Sechinato A., et al. "Effects of diet supplementation with organic trace minerals on production of laying hens". Brazilian Journal of Veterinary Research and Animal Science 16 (2006): 159-166.

20. Payne RL., et al. "Effect of inorganic versus organic selenium on hen production and egg selenium concentration". Poultry science 84.2 (2005): 232-237.

21. Hudson BP., et al. "Reproductive performance and immune status of caged broiler breeder hens provided diets supplemented with either inorganic or organic sources of zinc from hatching to $65 \mathrm{wk}$ of age". Journal of Applied Poultry Research 13.2 (2004): 349-359.

22. Ceylan N and Scheideler SE. "Effects of the eggshell-49, dietary calcium level and hen age on performance and egg shell quality". In biotechnology in the feed industry. Proceedings of Alltech's 15th Annual Symposium. University Press Nottingham (1999): 61-73.

23. Dale N and Strong Jr CF. "Inability to demonstrate an effect of eggshell \# 49 on shell quality in older laying hens". Journal of Applied Poultry Research 7.2 (1998): 219-224.

24. Mabe I., et al. "Supplementation of a corn-soybean meal diet with manganese, copper, and zinc from organic or inorganic sources improves eggshell quality in aged laying hens". Poultry Science 82.12 (2003): 1903-1913.

25. Upadhaya SD., et al. "Effects of supplementation of ionized or chelated water-soluble mineral mixture on the live performance, nutrient digestibility, blood profile, egg quality, and excreta microbiota of laying hens". Brazilian Journal of Poultry Science 18.2 (2016): 239-246.
26. Feng JW., et al. "Effects of zinc glycine chelate on growth, hematological, and immunological characteristics in broilers". Biological Trace Element Research 133.2 (2010): 203-211.

27. Berger LL and Cunha TJ. "Salt and trace minerals for livestock, poultry and other animals". Alexandria, Va, USA: Salt Institute (1993).

28. Sahin K., et al. "Supplementation of zinc from organic or inorganic source improves performance and antioxidant status of heat-distressed quail". Poultry Science 84.6 (2005): 882-887.

29. Lu J., et al. "Albumin as a zinc carrier: properties of its highaffinity zinc-binding site". Biochemical Society Transactions 36.6 (2008): 1317-13121.

30. Sitar ME., et al. "Human serum albumin and its relation with oxidative stress". Clinical Laboratory 59.9-10 (2013): 945-952.

31. Yenice E., et al. "Effects of organic and inorganic forms of manganese, zinc, copper, and chromium on bioavailability of these minerals and calcium in late-phase laying hens". Biological Trace Element Research 167.2 (2015): 300-307.

32. Leeson S. "Trace minerals in poultry nutition-2. Copper and zinc-the next pollution frontier". World Poultry 3 (2008): 1416.

33. Sun Q., et al. "Effects of methionine hydroxy analog chelated $\mathrm{Cu} / \mathrm{Mn} / \mathrm{Zn}$ on laying performance, egg quality, enzyme activity and mineral retention of laying hens". The Journal of Poultry Science 49.1 (2012): 20-25.

34. Leeson S and Caston L. "Using minimal supplements of trace minerals as a method of reducing trace mineral content of poultry manure". Animal Feed Science and Technology 142.3-4 (2008): 339-347.

35. Kiefer C. "Chelated minerals in poultry and swine nutrition". Nutritive Electronic Magazine 2.3 (2005): 206-220.

36. Manangi MK., et al. "Impact of feeding lower levels of chelated trace minerals versus industry levels of inorganic trace minerals on broiler performance, yield, footpad health, and litter mineral concentration". Journal of Applied Poultry Research 21.4 (2012): 881-890. 
37. Hashemi SR and Davoodi H. "Herbal plants as new immunostimulator in poultry industry: a review". Asian Journal of Animal and Veterinary Advances 7.2 (2012): 105-116.

38. Mirzaei-Aghsaghali A. "Importance of medical herbs in animal feeding: a review". Annals of Biological Research 3.2 (2012): 918-923.

39. Abiala M., et al. "Evaluation of therapeutic potentials of plant extracts against poultry bacteria threatening public health". BMC Complementary and Alternative Medicine 16.1 (2016): $1-8$.

40. Ezzat Abd El-Hack M., et al. "Beneficial impacts of thymol essential oil on health and production of animals, fish and poultry: a review". Journal of Essential Oil Research 28.5 (2016): 365-382.

41. Sridhar M., et al. "Effect of dietary resveratrol in ameliorating aflatoxin B1-induced changes in broiler birds". Journal of Animal Physiology and Animal Nutrition 99.6 (2015): 1094-1104.

42. Khan RU., et al. "Potential applications of ginger (Zingiber officinale) in poultry diets". World's Poultry Science Journal 68.2 (2012): 245-252.

43. Khan RU., et al. "Garlic (Allium sativum) supplementation in poultry diets: effect on production and physiology". World's Poultry Science Journal 68.3 (2012): 417-424.

44. Sridhar M., et al. "Effect of dietary resveratrol in ameliorating aflatoxin B1-induced changes in broiler birds". Journal of Animal Physiology and Animal Nutrition 99.6 (2015): 1094-1104.

45. Ren H., et al. "Synergistic effects of probiotics and phytobiotics on the intestinal microbiota in young broiler chicken". Microorganisms 7.12 (2019): 684.

46. Upadhaya SD and Kim IH. "Efficacy of phytogenic feed additive on performance, production and health status of monogastric animals-a review". Annals of Animal Science 17.4 (2017): 929948.

47. Ahmed M., et al. "Rhodiola rosea exerts antiviral activity in athletes following a competitive marathon race". Frontiers in Nutrition 2 (2015): 24.
48. Suryakumar G and Gupta A. "Medicinal and therapeutic potential of Sea buckthorn (Hippophae rhamnoides L)". Journal of Ethnopharmacology 138.2 (2011): 268-278.

49. Hernandez F., et al. "Influence of two plant extracts on broilers performance, digestibility, and digestive organ size". Poultry Science 83.2 (2004): 169-174.

50. Bakkali F., et al. "Biological effects of essential oils-a review". Food and Chemical Toxicology 46.2 (2008): 446-475.

51. Lin YT., et al. "Inhibition of Helicobacter pylori and associated urease by oregano and cranberry phytochemical synergies". Applied and Environmental Microbiology 71.12 (2005): 85588564.

\section{Volume 3 Issue 8 August 2021 (C) All rights are reserved by Bhagwat Vishwanath G., et al.}

